\title{
Seismic response to mining the massive ore body at South Deep gold mine
}

\begin{abstract}
N. Naicker
Goldfields

Mining currently takes place at depths of between $2400 \mathrm{~m}$ and $2650 \mathrm{~m}$ below surface at South Deep gold mine. The ore body comprises Witwatersrand conglomerates and varies from $1 \mathrm{~m}$ to $120 \mathrm{~m}$ thick and extends over several kilometres. A mining method, specific to the geometry of the ore body, is utilized and comprises an initial destressing cut followed by massive mining in the destressed shadow.

A high profile stoping (HPS) mining method was introduced to reduce or eliminate many of the mining difficulties experienced with the previous low profile stoping (LPS) method. A system of regional stabilising pillars, together with the placement of backfill is utilized to minimise seismic energy emissions. Improvements to the ground support to mitigate rockburst damage were introduced and further improvements are ongoing.

A mine-wide seismic system comprising 35 sensors is used to monitor seismic activity. Attempts to improve seismic monitoring include velocity calibrations, sensor orientation studies, more accurate determination of the attenuation factor $(\mathrm{Q})$ and batch reprocessing of data to ensure consistency across software versions.

In this paper, the level of seismic activity in relation to the level of production, inclusive of production ramp ups and stoppages, from different sections of the mine, is evaluated. The type and severity of damage to workings is assessed together with a comparison of peak particle velocities at the damage locations. Preconditioning, other rockburst risk mitigation strategies and the sources of seismicity (in particular the role of geological features), are assessed. The seismic hazard for different periods of time is calculated.
\end{abstract}

\section{INTRODUCTION}

South Deep gold mine is located approximately $45 \mathrm{~km}$ south-west of Johannesburg, in the Far West Rand region of South Africa. The location of the mine in relation to other mining operations in the region is shown in Figure 1. The workings are accessed from the surface through two shaft systems; the Twin Shaft Complex and the South Shaft Complex. The mining methods used at South Deep started with conventional mining (pre-1998), which later evolved to mechanized mining with various layouts for drifting and benching, low profile horizontal destressing with crush pillars and long hole stoping (LHS). The mining method was then changed during 2015-2016 to the current high profile destress with LHS. South Deep is designed to access and exploit one of the largest undeveloped ore bodies in the world. It is estimated that the current mineral reserves will be depleted by 2095, Gold Fields (2017). 


\section{Geological setting}

The South Deep orebody, currently being mined at $2400 \mathrm{~m}-2650 \mathrm{~m}$ below surface, forms part of the Witwatersrand Basin. The ore body is a shallow dipping ( $10^{\circ}$ to $15^{\circ}$ south) massive package with thicknesses ranging from $1 \mathrm{~m}$ to $120 \mathrm{~m}$ across on strike (West to east).

The reef horizons exploited at South Deep include the Ventersdorp Contact Reef (VCR) and the Upper Elsburg formation conglomerates. The Upper Elsburg reefs constitute $98 \%$ of the South Deep Reserves ounces, while the VCR makes up the remaining $2 \%$.

On the mine lease, a series of post depositional west-east trending faults are present. Different populations of dykes also network across the mine lease. Some dykes which are orientated roughly north-south, are near vertical and can attain thicknesses of up to $30 \mathrm{~m}$. The most significant of these are the Gemsbokfontein No 1 and No 2 dykes, which extend north-south through the property.

The South Deep lithology in Figure 1 shows the Ventersdorp lava above the VCR, overlaid by the Malmani Dolomite and Pretoria Group. The Upper Elsburg subcrop (UES) thins out to the west, at the $4 \mathrm{~W}$ corridor, and is at its widest at the $1 \mathrm{~W}$ corridor to the east.

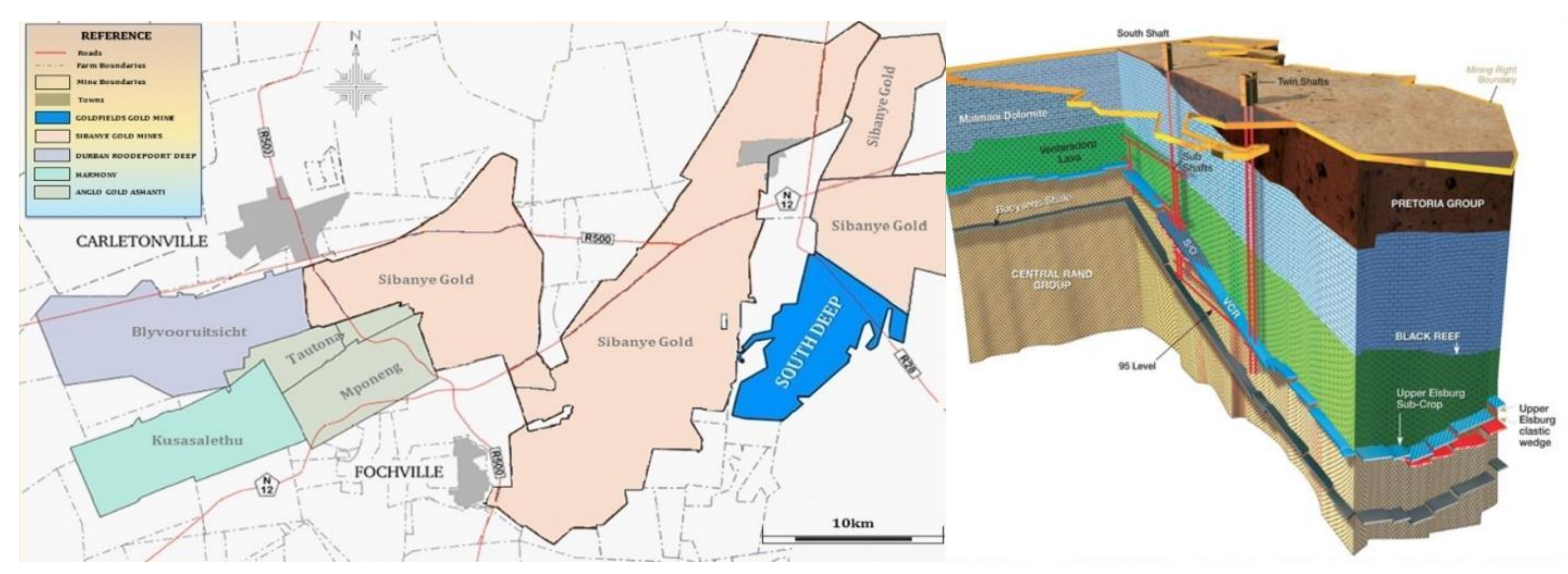

Figure 1. Location of South Deep in relation to other mining operations in the Far West Rand (left). 3D Schematic illustration of South Deep gold mine (right)

\section{MINING OF THE MASSIVE ORE BODY}

\section{Overview}

The mine's current operations consist of two primary mining areas, Current Mine and North of Wrench (NoW) shown in Figure 2. Different mining methods are applied in each area. The Current Mine area is defined by the previous tabular conventional mining area's footprint, the method that was previously applied to mine specific reef horizons within the Elsburg package. Mining activities are largely scattered over the whole of Current Mine area. These areas are accessed with normal development from existing ramps and extracted with drifts, benches and LHS. This footprint currently serves as a destress horizon for the application of mechanised mining methods in the form of drifts, benches and LHS with backfilling. These methods are used to extract the remaining massive reefs above and below these tabular mined-out horizons. The infrastructure developed for the conventional mining also serves partially to support the mechanised mining being applied. Mining operations in this area are selective and restricted to specific targets, taking into consideration geotechnical and access conditions, Gold Fields (2017).

The NoW area is situated down dip from Current Mine in a southern direction. It is largely unmined and a different method specifically designed for efficient massive extraction of the ore body is applied 
in this area. Mechanised horizontal destress mining, similar to room and pillar mining, constitutes the destress cut, after which the cut forms the platform for LHS to extract the massive targets above the cut. The area consists of six independent corridors within which the method is applied. NoW forms the mainstay of the mines medium-term life.

The South of Wrench (SoW) mining area will be exploited by a similar mining method (horizontal destress and LHS) applied in NoW. It is comprised of two mining blocks; SoW-East and SoW-West. Access to the SoW blocks requires significant capital infrastructure development.

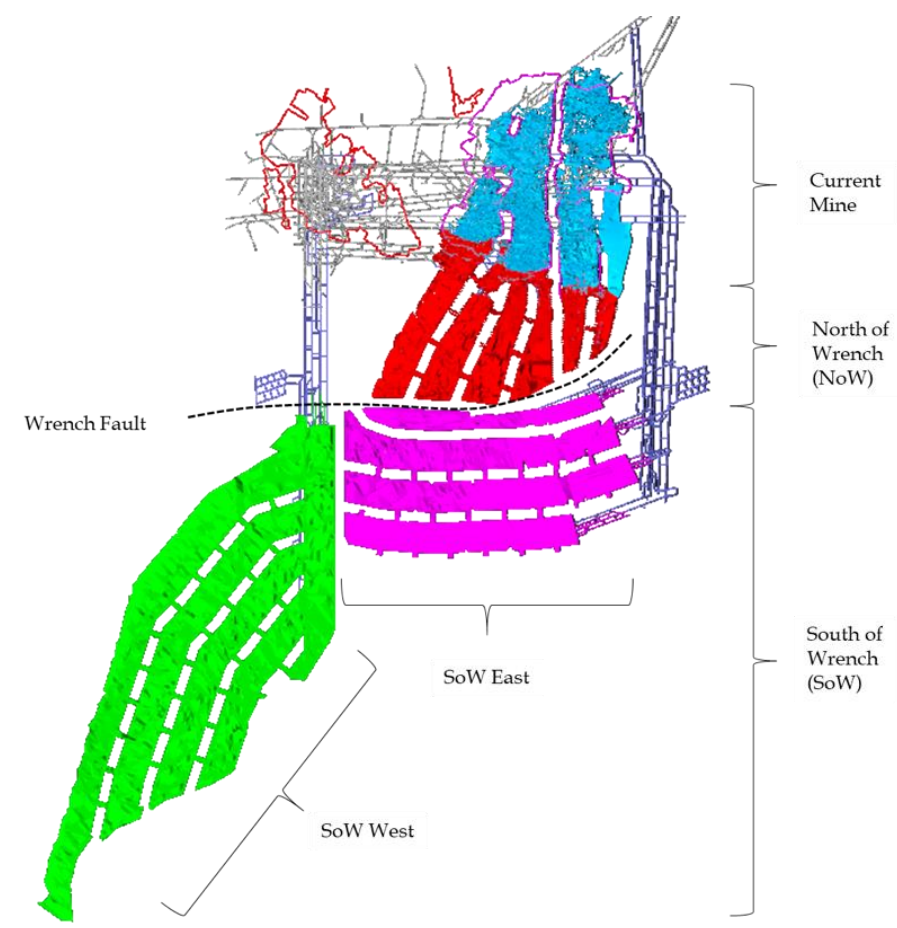

Figure 2. Plan view of South Deep showing the life of mine (LOM) design. The colours represent different mining phases

Three different mining methods are applied in this Elsburg area. Initially, a 5.5 metre-high horizontal slice is mined through the targeted reef package. This phase is referred to as destressing and the purpose of this phase is to destress the reef above and below this cut. The destressing of the reef allows for LHS without the high rock stresses associated with mining at depths of $2700 \mathrm{~m}$ to $3300 \mathrm{~m}$. These horizontal destress cuts are mined at $20 \mathrm{~m}$ vertical intervals and constitute $11 \%$ of the total reserve design. Mechanised destressing is only applicable to NoW and SoW.

LHS is accessed from the destress excavations and individual stope heights are limited in size to $20 \mathrm{~m}$ high and $66 \mathrm{~m}$ long. Where the reef targets are thicker than $20 \mathrm{~m}$, long-hole stopes are stacked with up to three long-hole stopes making an overall height of up to $60 \mathrm{~m}$. LHS makes up $69 \%$ of the total reserve design.

Where reef targets are thinner, between $5 \mathrm{~m}$ and $15 \mathrm{~m}$, a more selective mining method is required. Drifting and benching serves this purpose. Drifts are mined at a width and height of $6 \mathrm{~m}$ and $5.5 \mathrm{~m}$ respectively, the length varying depending on the target zone. Benches are mined from the drift's hang or foot up to heights (including the drift) of $15 \mathrm{~m}$. Drifting and benching constitute $9 \%$ of the reserve design. The remaining $11 \%$ of the reserve design comprises of on-reef access development. 


\section{Destressing}

At the depth of mining at South Deep, rock stresses become exceedingly high. Stresses are aggravated dramatically with large high excavations associated with massive mechanised mining, surpassing the rock strength and increasing the risk of rock bursts and sudden failure. To combat this occurrence, the ore-body should be mined with smaller excavations to drive the higher stress zones away from the large excavations and create a lower stress zone above and below the smaller excavations (Figure 3 ). A series of destress cuts are mined to create a lower stress environment for massive mining. Changes to the way the destress mining is carried out, inclusive increasing the mining height, have been implemented. The current HPS method uses $5.5 \mathrm{~m}$ high horizontal destress cuts, spaced at $20 \mathrm{~m}-25 \mathrm{~m}$ intervals, with $8 \mathrm{~m}$ x $20 \mathrm{~m}$ yielding pillars. The HPS method optimizes the extraction of the ore body by improving the production profile and mining efficiencies.

These destress cuts are developed into virgin stress rock with mechanised equipment on a grid pattern leaving yield pillars, similar to a room and pillar layout, and require dynamically yielding support (Figure 3 ). The pillars are designed to yield and not pose a significant rock burst risk; transferring stress in a reduced controlled manner to the footwall. The effect on the surrounding rock mass is an in-situ stress similar to shallower mines (equivalent to depths of $1 \mathrm{~km}$ to $1.5 \mathrm{~km}$ ), where large excavations can be mined. Figure 3 shows elastic stresses of $30 \mathrm{MPa}-40 \mathrm{MPa}$ in the destressed zone and mining induced stresses ahead of the destress mining fronts reaching as high as $500 \mathrm{MPa}$. These values were obtained from numerical modelling done in MAP3D.

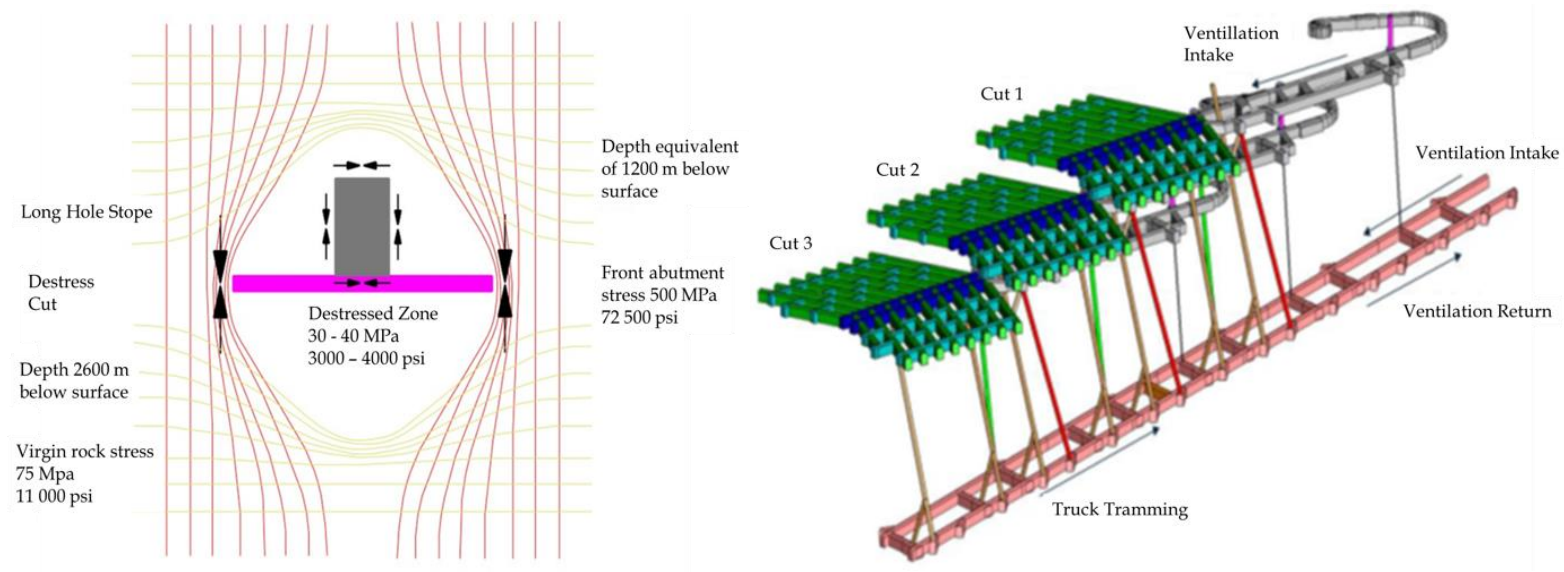

Figure 3 - Conceptual illustration of the destressing method (left). Horizontal destress cuts mined with $20 \mathrm{~m}$ vertical intervals on a grid pattern leaving crush pillars (right)

\section{Long hole stoping}

LHS is the primary method of excavating reef on South Deep. This is a very efficient method to extract the large volumes required to mine the thick Elsburg reef package. From the destress cut, LHS $(20 \mathrm{mH}$ $\times 13 \mathrm{~mW} \times 60 \mathrm{~mL}$ ) can take place to extract the remainder of the package to the cut above or the limit of the target zone. The method consists of a fan drilled radially from the strike access drive (SAD) and hole lengths designed such that the resulting excavation envelope takes on a block profile. Multiples of these fans or rings are then drilled and charged up, five rings at a time. The fans are blasted sequentially to break slices of rock forming the advancing face.

LHS is commenced from the SADs in the destress cut once the cut development has been completed. The first and second LHSs are mined from the central SADs on either side of the main access drives (MADs). When the LHS are completely extracted the voids are filled with backfill. The backfill is allowed to cure to provide adequate strength and stability before the remaining LHS areas are extracted sequentially towards the hangingwall and footwall of the ore-body. The LHS areas are backfilled continuously after extraction in the same sequence as being mined to increase geotechnical stability of surrounding rock mass. 


\section{Drift and bench mining}

The drift and bench mining method will be carried out predominantly in the west towards the suboutcrop of the Upper Elsburg package against the VCR, owing to the lower mining heights. Scattered pockets of high-grade targets are also planned to be extracted with this method where selectivity requirements demand for the ability to extract smaller targets. Figure 4 shows an illustration of all the mining methods at South Deep gold mine.

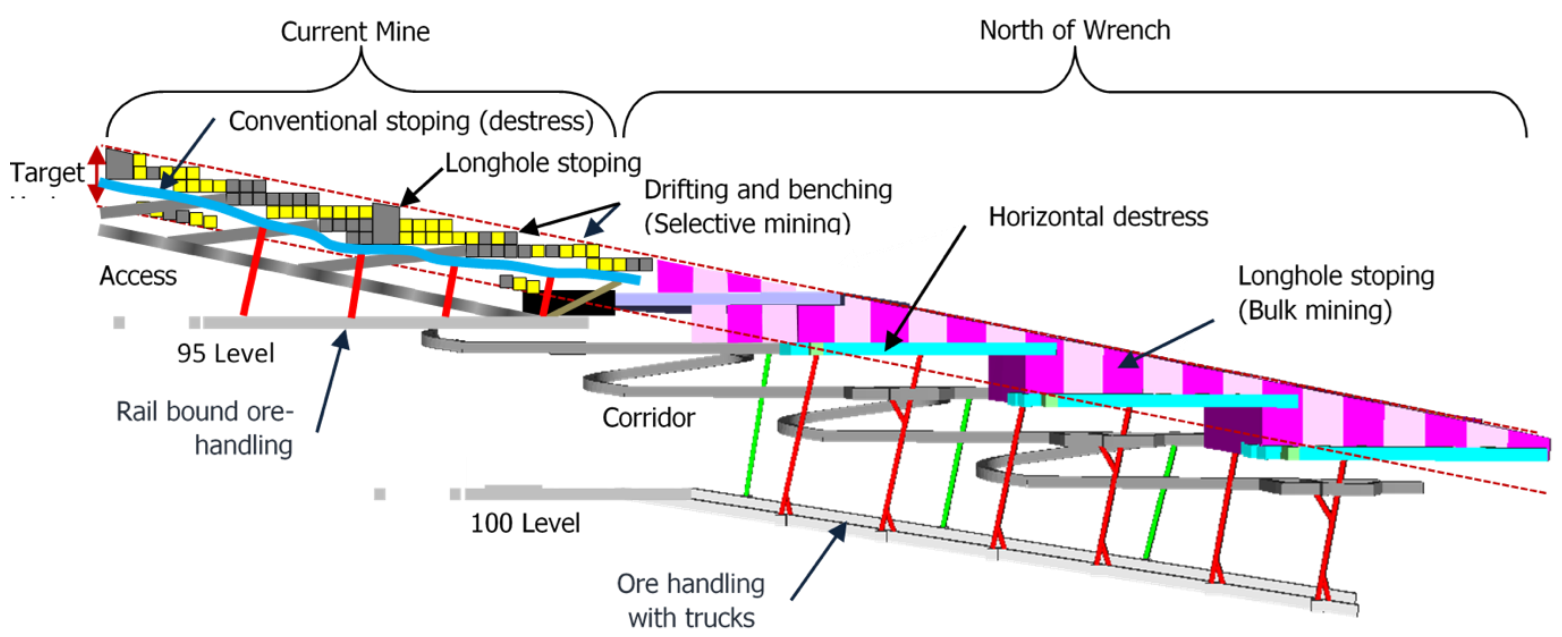

Figure 4 - A 3D schematic illustration of South Deep gold mine showing all the mining methods

\section{The evolution of mining at South Deep gold mine}

Over a period of eight years, design changes to improve mining efficiencies were undertaken. In the destress sections, there were changes to the mining height, from LPS to HPS, as well as changes to the type of pillars used, from crush pillars to yield pillars. The mining height increased from $2.2 \mathrm{~m}$ in LPS to $5.5 \mathrm{~m}$ in HPS and pillar sizes (lengths and widths) increased from $2 \times 4 \mathrm{~m}$ (crush) to yield pillars of two sizes, initially $6 \times 8 \mathrm{~m}$, followed by $8 \times 20 \mathrm{~m}$. Numerical modelling, underground measurements and observations (observational approach to design) were all used to evaluate any geotechnical changes before trial and implementation.

The mine also experienced periods of production stoppages. From May 2014 to July 2015 many sections of the mine had to halt production to rehabilitate secondary support. On 2 November, 2018, organized labour at South Deep embarked on a protected strike over retrenchments at the mine. The strike commenced at 17:00 on that day and was called off on 11 December 2018. The return to work was followed by the Christmas break resulting in mining activities only resuming early in 2019.

\section{THE SEISMIC SYSTEM}

The South Deep micro-seismic network consists of 33 geophones and 9 accelerometers. The area between Twin Shaft and South Shaft, of which the sw-ne cross section spans roughly $3.5 \mathrm{~km}$, is monitored by 35 seismic sensors and the remaining 7 seismic sensors monitor the water barrier (at the border of Sibanye Gold's Cooke 4 Shaft) about 2.7 km north-north-west of South Shaft. Figure 5 shows a plan view of the seismic network with seismic sensors depicted with numbered rectangles. The seismic system is designed to run continuously and record seismic events whenever they occur. Ground vibrations caused by seismic events are recorded by the sensors at each underground seismic site and are sent automatically to the seismic data acquisition server based on a triggering logic with a predetermined triggering threshold. If more than a minimum number of seismic sensors is triggered within a set time, the triggers are grouped as a seismic event and the waveforms are transmitted to 
surface via the mine's ethernet communication system. Sensors consist of both accelerometers and geophones and a program of network expansion is ongoing to provide seismic coverage for all mining areas. The system is relatively sensitive and records seismic events less than local magnitude $0.0\left(\mathrm{M}_{\mathrm{L}}\right.$ $0.0)$ throughout the active mining area. This is equivalent to the logarithm of seismic potency equal to 0.2. South Deep's local magnitude is defined in terms of seismic potency and seismic energy as follows:

$$
\mathrm{M}_{\mathrm{L}}=0.516 \log (\mathrm{P})+0.344 \log (\mathrm{E})-1.144
$$

Seismic events are then automatically processed, which involves the automatic picking of P-and S-wave arrivals on seismograms and calculation of the seismic source location and source parameters. The automatically processed seismograms are then saved to the database. Routine manual seismic data processing is carried out at the Institute of Mine Seismology (IMS) by seismic data processors. The status of all sensors, seismic system health and operational status is communicated to the mine by means of daily reports. These performance criteria are calculated from power, communications, timing and the status of individual components of seismic sensors. Automatic backups of all data and strategic directories (such as configuration files and system files ) are performed by the IMS.

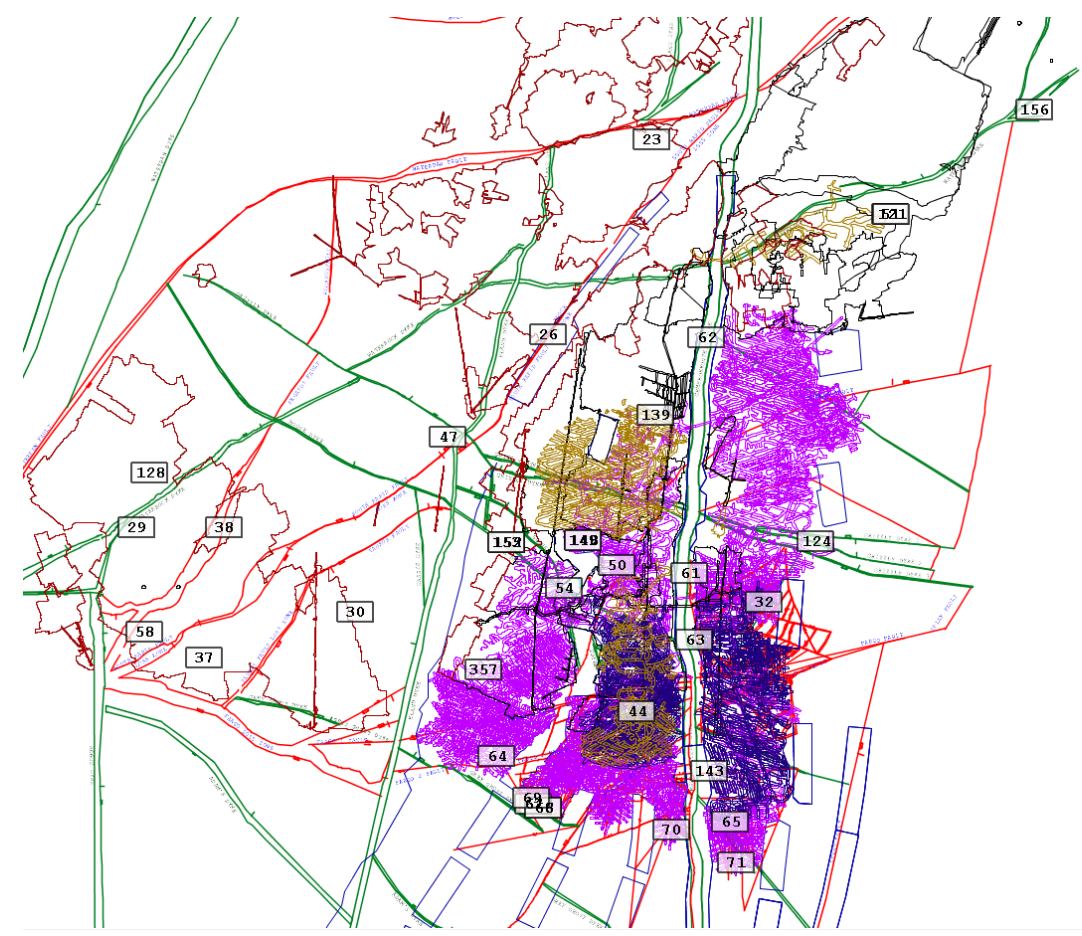

Figure 5 - The seismic network at South Deep. In some instance two sensors are installed in a single borehole

\section{Seismic network and data quality improvements}

Two important issues were identified to improve the seismic monitoring programme at South Deep. It was observed that seismic event locations did not always correlate to active mining - especially when viewed in 3D. The source parameters of seismic data showed sudden jumps when viewed over longer time periods. The most critical process was to improve the three-dimensional nature of the seismic network to help provide more accurate source locations and to record a better sampling of the seismic radiation pattern that would result in improved source parameters. A second improvement identified was the need to improve the quality of historical and future recorded data. 


\section{Improving the seismic network}

The seismic network at South Deep consisted of sensors installed mostly in the footwall of haulages at relatively similar elevations. Although some sensors were installed at shallower depths, they are all situated at the mine shafts - some considerable distance away from where current mining is conducted. Due to the planar nature of the seismic network the seismic event locations were not as accurate in the depth direction $(Z)$ as desired. Although the locations in plan (Horizontal $X$ and $Y$ directions) were found to be located within $30 \mathrm{~m}$ for events within the network, the location in $\mathrm{Z}$ was at times exceeding $50 \mathrm{~m}$. These values were confirmed when comparing actual event locations to the theoretical network design simulations. Seismic event locations ahead of the mining front were also inaccurate due to the mining being ahead of the seismic sensors. As mining progresses it would essentially be outside the seismic network. This situation makes it difficult to accurately quantify the distance ahead of the destress mining faces where seismicity is occurring, and as result, makes it difficult to identify sources of the seismic events (geological structures) and to determine the actual seismogenic zone.

The solution to this problem was to install additional seismic sensors in the destress mining sections. Installing sensors in an active mining area can be risky because of the damage that can be expected to the sensor cabling and the sensors themselves. This damage is mostly due to moving machinery and other routine mining activities. Another significant risk is that the sensors in the destress section can be damaged by being too close to the source of large magnitude seismic events. Nevertheless, it was decided to proceed with this strategy and sensor installations in the hangingwall of the destress cuts have been successful. With four of the five installations completed an improvement in $\mathrm{Z}$ location and better clustering of seismicity has been noticed in these areas. However, one sensor lost two components due to a $\mathrm{M}_{\mathrm{L}} 1.9$ seismic event nearby and requires replacement. Further sensor installations are planned using geophones installed in long boreholes drilled into the footwall of the destress cuts. It is also expected that multiple types of sensors will be deployed to better cover the range of frequencies generated by different magnitude seismic events.

\section{Improving the quality of recorded seismic data}

Improving the quality of recorded seismic data comprises improving the location and source parameters of seismic events. The IMS was tasked to carry out a study to address these two aspects in the historical data set of South Deep and, following review and consultation, to make the necessary changes that will result in the improvement of future seismic data that is recorded. The study was carried out by Clark and Gerber (2018) and consisted of three parts:

- the seismic velocity inversion using the adaptive apparent velocity method (AAVM);

- the batch reprocessing of the historic events; and

- the inversion of sensor orientation.

\section{VELOCITY CALIBRATION}

\section{The adaptive apparent velocity method}

The previous velocity model for South Deep assumed homogeneous (uniform) seismic wave velocities throughout the entire rock mass as input for solving for the locations of seismic events. This is not an optimal situation for a rock mass that is anisotropic as is the case at South Deep. The AAVM utilises a set of calibration blasts or seismic events to identify, and account for, localised velocity variations on a per region and per sensor basis.

The apparent velocity is the velocity with which a seismic wave appears to travel from the source to the sensor assuming a straight-line travel path with no corrections. It will exceed the actual velocity if the wave does not travel directly from the source to the sensor. The AAVM is a location-dependent and sensor-specific apparent velocity model. It is more realistic and should provide better event locations compared to the previous single-velocity model. The results are only applicable within the volume defined by the calibration blasts and new calibrations blasts $\backslash$ events will be required as mining progresses. 


\section{Results}

Since it is known that most seismicity at South Deep occurs on the reef horizon, the orthogonal distance to reef was selected as a measure to quantify the improvement in seismic event locations. A comparison was carried out between the original locations, produced by seismological processing software (IMS Trace), and the AAVM locations. The results, included in Table 1, show the orthogonal distance to the top of the destress cuts of the ore body for six different areas. Three statistical measures; mean, median and $90^{\text {th }}$ percentile, were used to quantify the improvement and show that there was a decrease in distance to reef for seismic event locations in all mining areas. The AAVM locations are, on average, across all evaluation areas and $30.2 \%$ closer to the stoping horizon compared to the previous locations calculated with a single-velocity model.

These results were interpreted to indicate that there is a definite improvement in the location accuracy of these seismic events. The improvement was most significant for the $1001 \mathrm{~W}$ mining area. The $90^{\text {th }}$ percentile is an indication of the distance from reef for typical outlier events. The improvement observed is a positive result and the AAVM has been implemented for routine seismic data processing for South Deep since December 2018. Historic events have been batch reprocessed using the calibrated velocities.

Table I - A comparison of orthogonal distances to reef of the current and the AAVM locations for selected areas of the mine, with 10 or more triggers, for events between 1 June to 31 July 2018

\begin{tabular}{|c|c|c|c|c|c|c|}
\hline \multirow{2}{*}{ Area } & \multicolumn{2}{|c|}{ Mean (m) } & \multicolumn{2}{c|}{ Median (m) } & \multicolumn{2}{c|}{$90^{\text {th }}$ Percentile (m) } \\
\cline { 2 - 7 } & Current & Adaptive & Current & Adaptive & Current & Adaptive \\
\hline All stoping & 40.1 & 28.0 & 30.5 & 18.2 & 94.3 & 70.1 \\
\hline $1001 \mathrm{~W}$ & 54.4 & 23.1 & 40.5 & 13.1 & 136.8 & 59.5 \\
\hline $100-2 \mathrm{~W}+3 \mathrm{~W}$ & 46.7 & 33.3 & 35.0 & 27.9 & 90.7 & 69.2 \\
\hline 100-4W & 38.2 & 20.2 & 27.9 & 20.2 & 101.0 & 59.2 \\
\hline 90_95-1W & 60.0 & 44.3 & 32.1 & 19.9 & 158.3 & 84.8 \\
\hline 90_95-2W+3W & 68.8 & 51.8 & 35.5 & 25.8 & 185.1 & 157.4 \\
\hline 87 90 Back area & 90.1 & 63.4 & 60.5 & 48.6 & 225.4 & 106.2 \\
\hline
\end{tabular}

\section{Batch reprocessing}

Batch reprocessing involved the relocation of 254044 seismic events, using the AAVM and the recalculation of source parameters. The source recalculation was performed using the recommendations from the South Deep hazard report, Green and Gerber (2018) which recommended using an upper cutoff frequency of $800 \mathrm{~Hz}$ and a fixed attenuation $Q$ parameter $\left(Q_{S}=300\right.$ and $\left.Q_{P}=600\right)$. The $Q$ parameter represents the frequency-dependent attenuation factor for a given rock type. It was observed that, in general, the automatic $Q$ inversion algorithm, which inverts the quality factors $\left(Q_{P}\right.$ and $Q_{S}$ used for attenuation) from the recorded waveforms, yielded a higher corner frequency $\left(\mathrm{f}_{0}\right)$. The higher $\mathrm{f}_{0}$, in turn, resulted in large magnitude seismic events being reported as having a lower magnitude.

In order to compare the change between the original and batch reprocessed data the seismic energy (E) versus seismic potency $(P)$ was plotted. Figure 6 shows the $\log (E)$ vs $\log (P)$ plot of the original (blue) and source recalculated (green) seismic events. The $\log (\mathrm{E}) \mathrm{vs} \log (\mathrm{P})$ plot shows a much better fit for the smaller seismic events. The source could not be calculated for roughly 300 of the $\log (\mathrm{P})<-5.0$ events. For the smaller events the energies are often overestimated as can be seen by the variation in energies 
in the figure. Smaller events trigger fewer seismic sensors and their waveforms have a lower signal to noise ratio. Seismic sensors have limited capability to record the high frequencies that contribute to the radiated seismic energy of small events, Mendecki (2013). With larger events there is a higher signal to noise ratio and $\log (\mathrm{P})$ is well constrained.

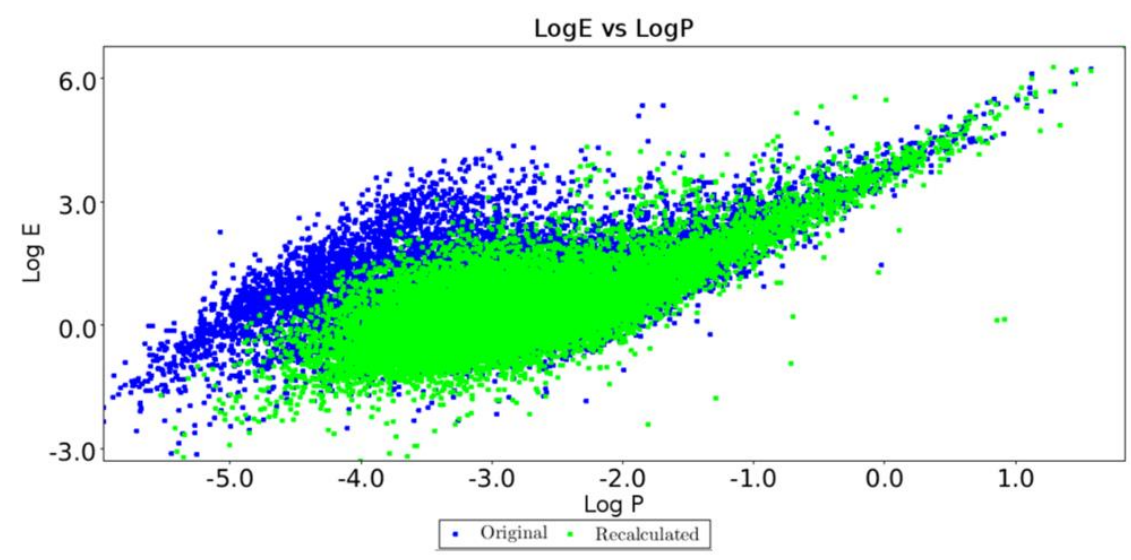

Figure 6 - $\log (E)$ vs $\log (P)$ of the original (blue) and source recalculated (green) seismic events

\section{Sensor orientation}

The purpose of the sensor orientation inversion is to improve the accuracy and reliability of source mechanisms at South Deep gold mine. The orientation of a seismic sensor is defined in terms of its azimuth, dip-offset and roll. These parameters could be affected by unintended roll during sensor installation or deformation in the rock mass where the sensor is installed. Seismic data can be used to invert the sensor orientation to account for these changes. The angular misfit is defined as the angle between the vector from the sensor to the event and the polarized vector of the seismic P-wave arrival. The polarization, Jurkevics (1988), is performed separately over all three components in the time domain.

\section{Inversion event selection}

The most recent and well spatially representative distribution of the events were selected for the sensor inversion. The inversion dataset contained 70 handpicked seismic events and blasts with the optimal spatial distribution and reliable locations. The inversion dataset was carefully reprocessed to minimize the location error and confirm the P-wave pick for each sensor. An important measure of the reliability of the sensor orientation is to calculate the average misfit for events that are not in the original inversion dataset (out-of-sample). The out-of-sample dataset contained over 1600 seismic events from the same period as the inversion dataset events.

\section{Results}

Figure 7 shows the distribution of angular misfits for the out-of-sample dataset before (left) and after (right) performing the sensor orientation inversion. Accelerometer sensors, uniaxial sensors and triaxial sensors with non-functional components were excluded from the inversion. 

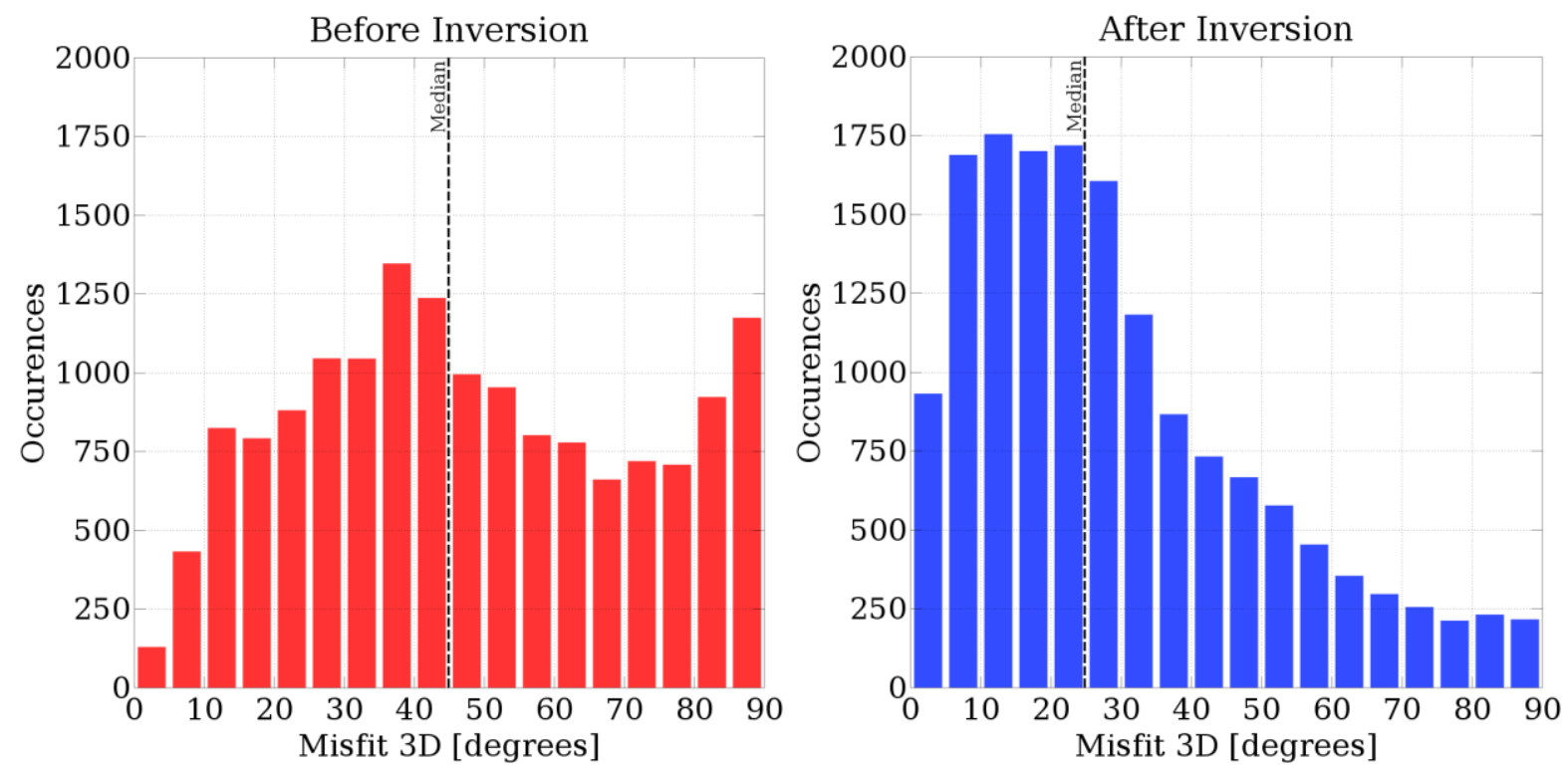

Figure 7 - Distribution of angular misfits for the out-of-sample dataset before (left) and after (right) the sensor orientation inversion

The inverted sensor orientations yield a significantly smaller angular misfit (on average) for more than 1600 out-of-sample seismic events. The median of the angular misfits decreased from $44.9^{\circ}$ to $24.8^{\circ}$, and the corresponding mean decreased from $47.7^{\circ}$ to $29.5^{\circ}$. A larger angular misfit in $3 \mathrm{D}$ (compared to the $\mathrm{XY}$ plane) may be associated with location uncertainty in the (immediate vicinity of the sensor) and/or so-called "ray bending" near the fractured excavations. Sensors with a 3D misfit smaller than $25^{\circ}$ are considered for moment tensor inversion.

\section{Seismic response to production}

The comparison of seismicity with production was separated into two different production sources, viz. the destress and the massive mining sections. A number of different seismic parameters were used to compare with production data from these two mining method sources but only the most useful results are reported on here.

\section{Seismicity vs destress mining production}

It was found that the seismicity, in terms of number of events of $M_{L} \geq 0.0$, showed a good correlation with production from the destress mining sections. The magnitude threshold, $\mathrm{M}_{\mathrm{L}} \geq 0.0$, was selected to reduce the effect of seismic system sensitivity on the amount of data recorded. Events of these magnitudes are expected to trigger the entire seismic network. Figure 8 shows a graph of destress production, in tonnes, and number of seismic events of $\mathrm{M}_{\mathrm{L}} \geq 0.0$ per month over a period of eight years. The major changes are captured at the top of Figure 8 and indicate the dominant activity for that period. It commences with horizontal destress with no pillars followed by the introduction of crush pillars in the horizontal destress (LPS) and ends with HPS with $8 \mathrm{~m} \times 12 \mathrm{~m}$ yield pillars. In between these two stoping periods, there was a period of transition from LPS to HPS where hangingwall ripping was undertaken to achieve the increase in mining height to cater for mining machinery to be used for HPS. During the period of secondary support rehabilitation (SSR) from April to November 2014, the seismic activity showed a noticeable decrease due to the associated decreased output in production from both the destress and massive mining sections. The labour strike in November and December 2018 resulted in a much lower rate of seismic activity when compared to periods of active mining. 


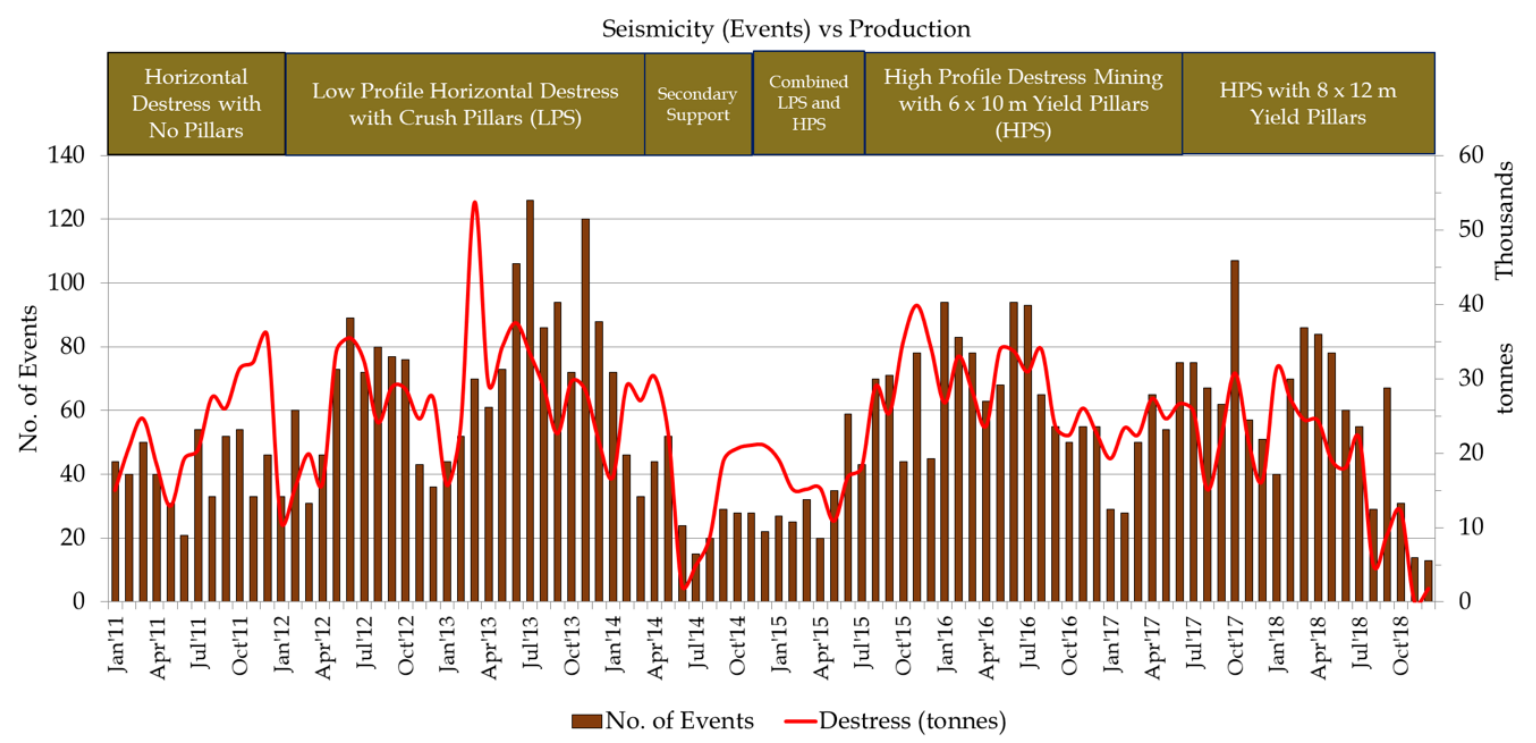

Figure 8. Seismicity vs production from the destress mining.

\section{Seismicity energy vs production}

Figure 9 shows the seismicity, in terms of energy released, plotted together with destress and massive mining production for the same eight-year period. The selection of seismic events included in the analysis, was again events with $\mathrm{M}_{\mathrm{L}} \geq 0.0$, but since larger seismic events release most of the energy, they contribute most to the sum of seismic energy for a particular month of production. Immediately apparent from the graph, is a distinct period between March and November 2013, where much higher seismic energy was released. At the start of this period, in March 2013, there was a peak in production tonnages from both the destress and the massive mining sections. The increased production volumes contributed, in part, to the higher seismic energy release that followed.

A second contributing factor was where the mining took place. An examination of the locations of the large seismic events during this time period showed concentration in two mining areas; the $903 \mathrm{~W}$ pillar and the $90 \mathrm{WW}$ area. The $90 \mathrm{3W}$ pillar is an isolated block of ground surrounded by a mined-out area. Destress mining was done on a portion of the pillar and massive mining took place around it in the destressed ground. The destress mining had the effect of increasing the stress levels on the remaining portion of the pillar, while the massive mining is thought to have decreased the width to height ratio of the pillar, further weakening the pillar. In the case of the $90 \mathrm{1W}$, mining was in the vicinity of the Gemsbokfontein Dyke stability pillar zone. Stress changes from the $901 \mathrm{~W}$ mining caused seismicity on the dyke-stability pillar.

\section{The labour strike in 2018}

The period of the labour strike (2 November to 11 December 2018) served as a good case study to observe rock mass behaviour when no mining activity takes place. Although no mining activity took place during this period, seismic activity continued to occur. Figure 10 shows the locations of 22 events of $\mathrm{M}_{\mathrm{L}}$ $\geq 0.0$ recorded in the mining areas during this period. The locations of these seismic events show that they were concentrated on regional stability pillars and ahead of the mining front, suggesting they were related to areas of higher stresses. 


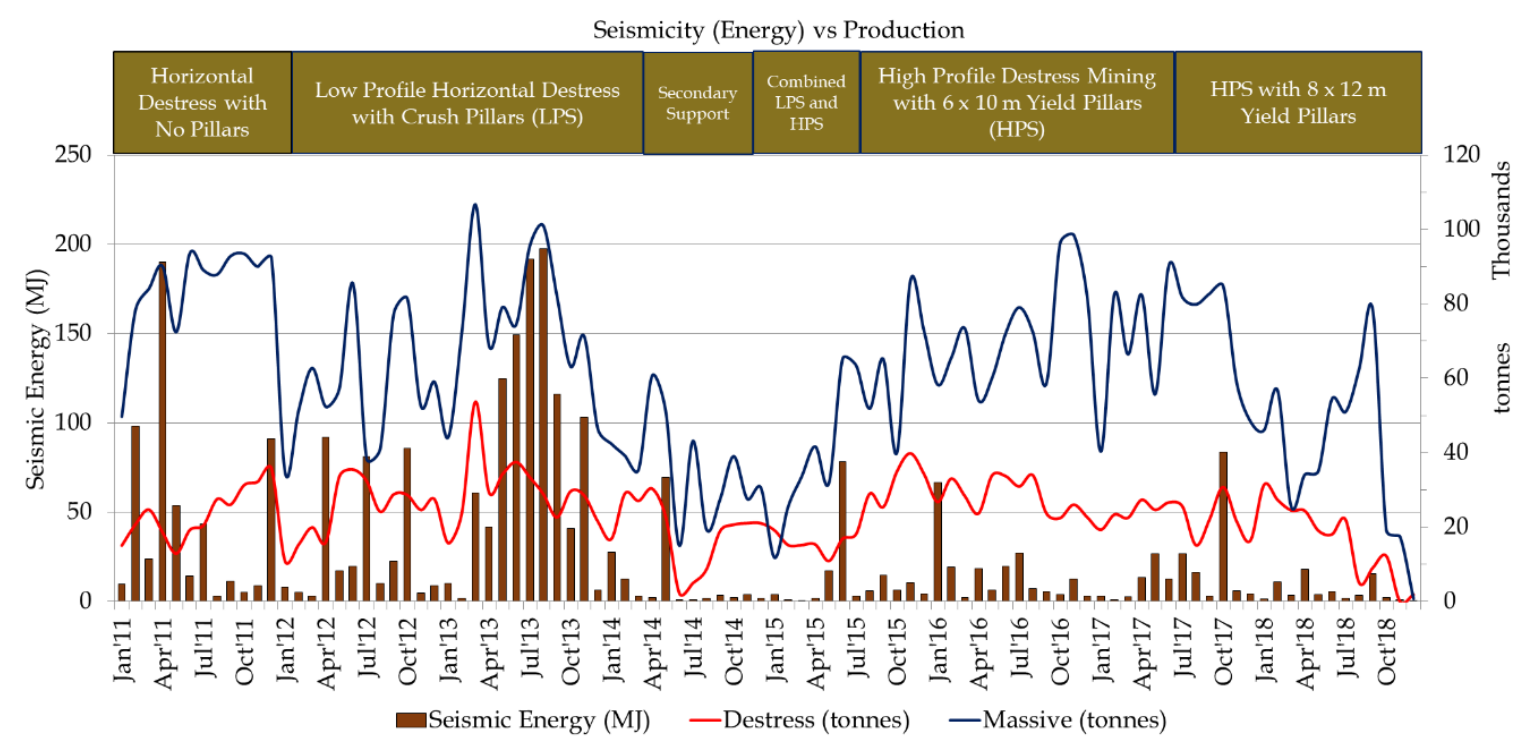

Figure 9. Seismic energy vs production from the destress and massive mining sections

Figure 10 shows the daily activity rate of seismicity during the labour strike. The bar graphs show the daily number of events for all magnitude events and the line graph in red is the moving average. A somewhat surprising observation was that the seismic activity rate took a fairly long time to decrease. Seismic events of $\mathrm{M}_{\mathrm{L}} \geq 0.0$, together with their aftershocks, continued to occur periodically during the strike period. This suggests that closure in the mined-out areas continued to occur, transferring stresses onto neighbouring regional stability pillars, abutments and the mining front.
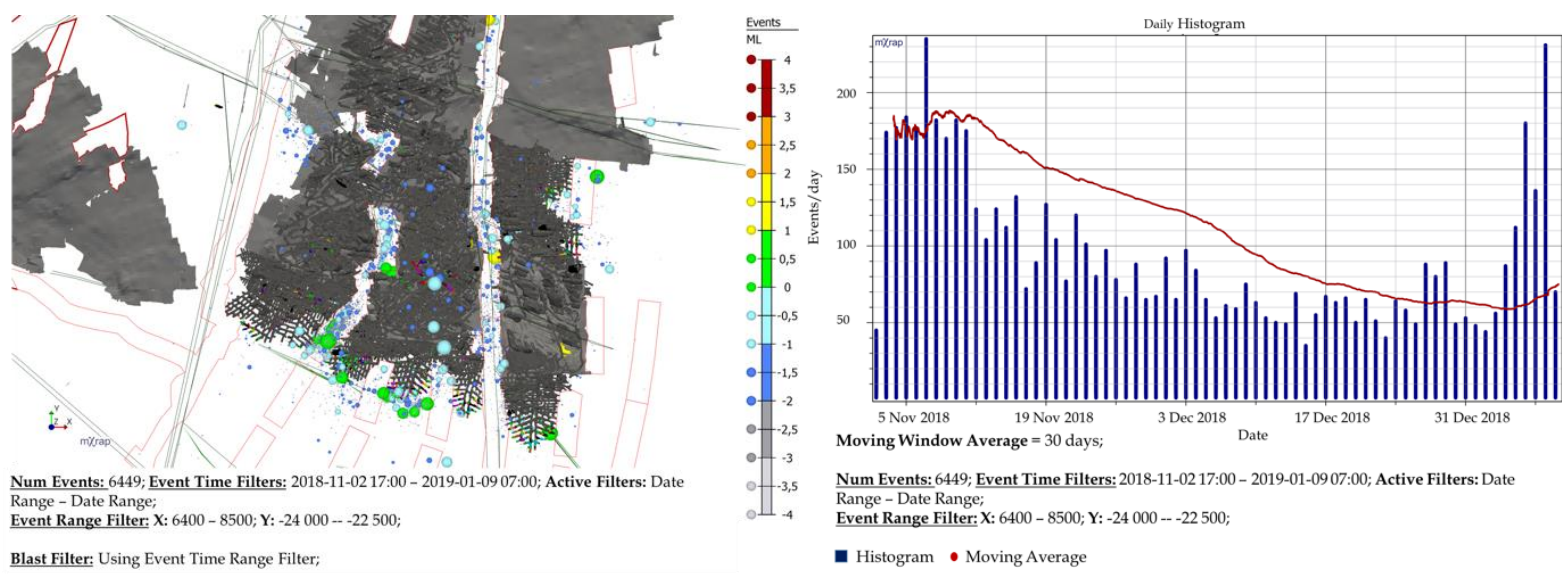

Figure 10. Location of seismic events during the strike (left). Seismic activity rate during the strike period (right)

\section{Rockburst damage and peak particle velocities}

Damage from seismic events is much more frequent in the destress sections compared to the massive mining section. During 2018, all 26 damaging seismic events occurred in the destress sections. The most common magnitude range for damage was from $\mathrm{M}_{\mathrm{L}} 0.5$ to 2.0 and damage predominantly occurred from the sidewalls with no injuries to workers. An assessment of peak particle elocities (PPVs) of seismic events at the location of the damage showed that they ranged from 0.05 to $0.2 \mathrm{~m} \backslash \mathrm{s}$. 
A comparison of these PPVs with expected damage showed that the damage was more severe than expected. This suggest that factors other than PPV influence the location and severity of damage. Potvin and Wesseloo (2013), cite the radiation pattern, interaction between seismic waves, geology, mining excavations, local site effects and the phenomenon of triggering of localized seismic events for this anomaly.

The response of South Deep gold mine to damaging seismic events was to focus more on the planning of mining sequences, the control of leads and lags, managing rates of advance and maintaining support compliance audits. Additional measures included preconditioning the destress mining faces, a system of centralized blasting and shotcreting.

Preconditioning is a rockburst control technique that involves setting off designed blasting ahead of the stope face. The technique is intended to transfer the mining induced stresses further away from the mining face through remobilizing of the pre-existing fractures in the rock mass Toper et al (2000). The four face-perpendicular preconditioning hole method practiced at South Deep was evaluated and later replaced by the five face-perpendicular preconditioning hole method. This change was introduced to get better interaction between the individual holes so that they function as a system to prevent strain energy or lock ups. To date, no face bursts have been observed from mining faces where preconditioning was practised.

Centralised blasting was introduced at South Deep and is at an advanced stage of implementation. The blasts between corridors are staggered in time and are accurately recorded, in time, by the seismic network. However, it has been observed that some of the blasts within a corridor effectively set off instantaneously, are missed by the seismic network. Because they occur so close in time, the seismic system is unable to associate seismic triggers from individual sites into seismic events or blasts.. Centralized blasting helps to contain most of the seismic activity within a shorter time period and some of the corridors have exhibited a strong blast time response. In addition, the blast data will be an excellent database for future seismic velocity calibrations.

The recent introduction of shotcrete has shown encouraging results in that damage from seismic events are not observed in areas that have been shotcreted. Figure 11 shows damage from a seismic event of $\mathrm{M}_{\mathrm{L}} 1.3$ where rock was dislodged from the sidewall. Shotcreted areas had no damage and the damage occurred only in a part of the excavation that was yet to be shotcreted.

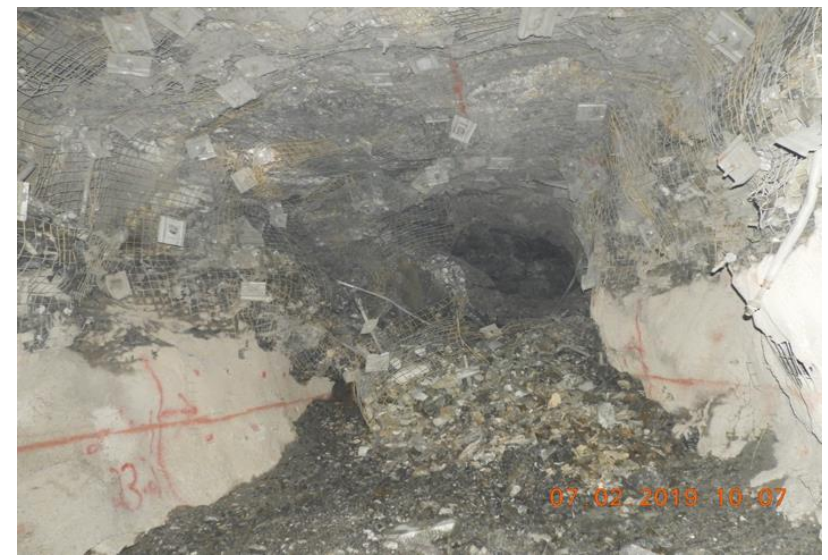

Figure 11 - Damage to sidewall of a SAD from a $M_{L} 1.3$ seismic event. No damage was observed in shotcreted areas 


\section{Seismic hazard}

For mines, the probabilistic seismic hazard assessment (PSHA) is frequently limited to the estimation of the probabilities that a potentially damaging event above certain magnitude; $\mathrm{M}_{\mathrm{L}}$, will occur within a mine or a given seismogenic volume of rock in future time $\Delta \mathrm{T}$, or while extracting a given volume of rock $\Delta \mathrm{V}_{\mathrm{m}}$, i.e. $\operatorname{Pr}\left[\geq \mathrm{M}_{\mathrm{L}} ; \mathrm{T}\right.$ or $\left.\Delta \mathrm{V}_{\mathrm{m}}\right]$. It is frequently called the size distribution hazard, Mendecki (2016).

\section{Short-term seismic hazard}

The short-term seismic hazard analysis, carried out daily, is an attempt to rate working areas on the mine that have a higher seismic hazard and the potential to experience seismicity. Specialized software is used by the IMS to analyse time histories of seismic parameters and large event occurrence $\backslash \mathrm{s}$ to identify any significant changes in the spatial and temporal behaviour of seismicity for different mine polygons. These changes could indicate the potential for large magnitude seismic events which may result in rockbursts. The scores assigned to the changes in individual seismic parameters are added up to give a total score (rating) for the polygon. Mining personnel follow a seismic rating checklist and the workings are stopped if the rating is high. These daily seismic hazard ratings are not an attempt to predict seismicity. The ratings often increase to high after a large seismic event or higher level of seismicity in an area. Underground employees are withdrawn from these workings to prevent injuries from aftershocks and return only when the ratings decrease to intermediate or low values. A high rating is inferred to mean that the probability of seismic activity in the short-term is higher.

\section{Intermediate- and long-term seismic hazard}

Green and Gerber (2018), carried out an intermediate- and long-term seismic hazard assessment for South Deep gold mine. Data was separated into two data sets to assess seismic hazard with regards to changes over time and volume mined. Analysis of seismic data recorded in the stoping region of the mine was reprocessed and data quality assessed.

The two largest events recorded were of $\log \mathrm{P}=2.83$ on 02 September 2013 and $\log \mathrm{P}=2.90$ on 28 April 2012 (Figure 12). The expected range of the next record-breaking event is $3.07 \leq \log \mathrm{P}_{\mathrm{nrb}}<3.25$ (highlighted in grey in Figure 12). The probability of the next record-breaking event to occur within one year is $15 \%$ and within 2 years is $27 \%$. Seismic hazard increased for medium sized events $(1.0 \leq \log \mathrm{P} \leq$ $2.0)$, between the first and second data sets, however hazard for larger events $(2.0 \leq \log P \leq 2.5)$ remained comparable between the two data sets. This implies that presently medium sized events are more likely to occur, than in the past, but larger events have a similar likelihood to occur than in the past.

Expected next record breaking $\log \mathrm{P}$

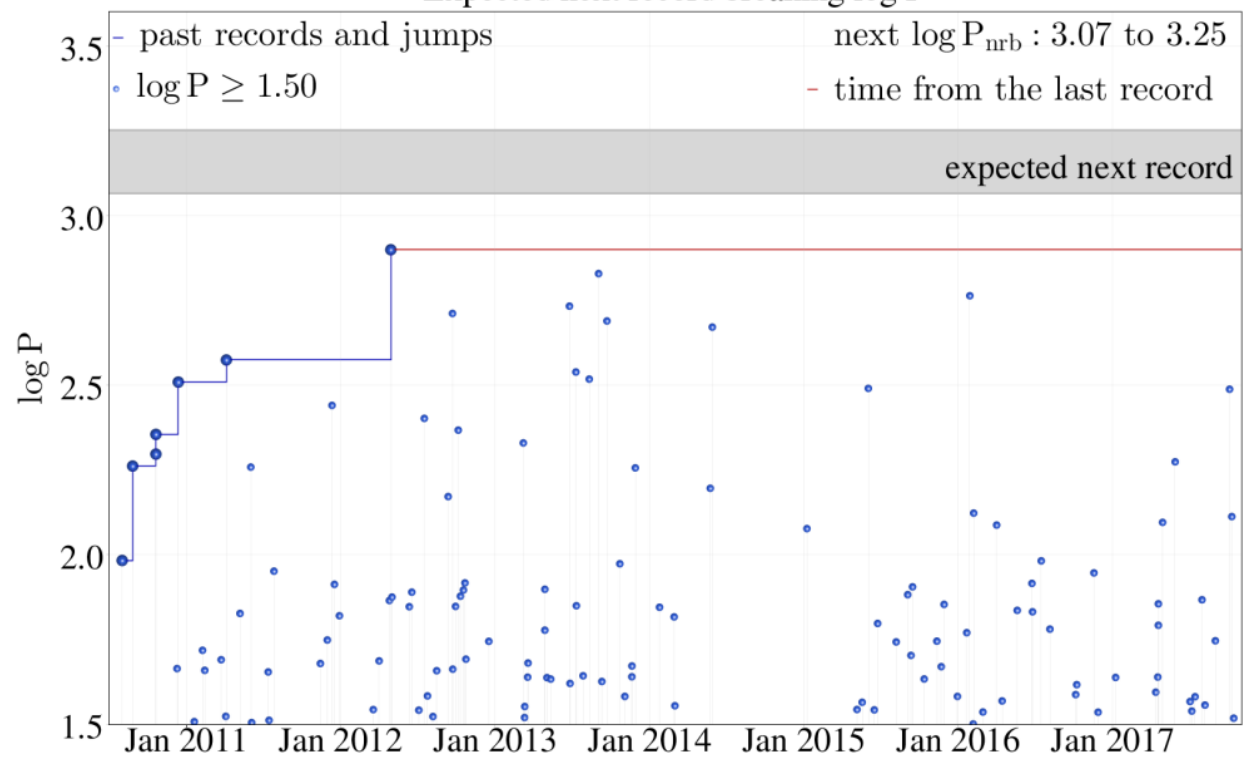

Figure 12. Expected next record-breaking $\log P$ 


\section{CONCLUSIONS}

Mining at South Deep gold mine consists of a series of destress cuts followed by LHS in the destressed shadow. A system of yield pillars and dynamically yielding support is used to provide geotechnical stability in the destress cuts. The voids created by LHS, extracted sequentially towards the hangingwall and footwall of the ore-body, are backfilled continuously to increase the stability of surrounding rock mass.

Improvements to seismic monitoring consists of an on-going strategy of network expansion to improve depth $(Z)$ locations and provide improved seismic information ahead of the destress mining front. The work on velocity calibration, batch processing, fixing the upper cutoff frequency, fixing the $Q$ parameters and sensor orientation studies all serve to improve the quality of seismic data recorded.

It was found that the seismicity, in terms of number of events of $\mathrm{M}_{\mathrm{L}} \geq 0.0$, showed a good correlation with production from the destress mining sections. Periods of higher production showed increases in the number of events recorded and seismic activity decreased significantly during periods of production stoppages. The seismicity in terms of energy released showed a good correlation with the amount of production, from both destress and massive mining, as well as from where the mining took place. Mining of ground that had higher stresses, or in close proximity to such areas, resulted in higher seismic energy released. The presence of geological structures also played a role in seismic energy release. Higher seismic energy releases, dominated by the contribution from larger seismic events, were observed when higher production was achieved from these areas, or immediately thereafter.

Seismic hazard at South Deep mine is driven mainly by the seismic rock mass response to mining and major geological structures near active mining. Medium sized events are more likely to occur, than in the past, while larger events will occur with a similar likelihood as in the past. The upper limit to the next record-breaking potency for South Deep mine, calculated using all data, has a log Pmax of 3.25.

\section{REFERENCES}

Clark, R. and Gerber, J. (2018). Velocity Calibration and Sensor Orientation for South Deep Mine Gold Fields. Report No. SDM-REP-VelocityCalibration-201810-IMSv0 (004). Institute of Mine Seismology, Stellenbosch, SA. 12 pp.

Gold Fields (2017). The Gold Fields Mineral Resources and Mineral Reserves Supplement to the IAR 2017. https://www.goldfields.com/pdf/investors/integrated-annual-reports/2017/mrr2017-hires.pdf, [Accessed 18 Feb. 2019].

Green, M. and Gerber, J. (2018). Intermediate- and Long-Term Seismic Hazard at South Deep Mine. Report No. SDM-HAZ-REP-201711-MGv0. Institute of Mine Seismology, Stellenbosch, SA. 11 pp.

Jurkevics, A. (1988). Polarization analysis of three-component array data. Bulletin of the Seismological Society of America. October 1988. Volume 78, No. 5, pp. 1725-1743.

Mendecki, A. J. (2013). Frequency range, $\log \mathrm{E}, \log P$ and magnitude. Proceedings of the 8th International Symposium on Rockbursts and Seismicity in Mines. September 2013, pp. 167-173.

Mendecki, A. J. (2016). Mine Seismology Reference Book: Seismic Hazard, 1 ed. Institute of Mine Seismology. ISBN 978-0-9942943-0-2, www.imseismology.org/msrb/. 3

Potvin, Y., and Wesseloo, J. (2013). Towards an understanding of dynamic demand on ground support. The Journal of The Southern African Institute of Mining and Metallurgy, Volume 113, December 2013, pp. 913-922. 
Toper, A.Z., Kabongo, K.K., Stewart, R.D., and Daehnke, A. (2000). The mechanism, optimization and effects of preconditioning. The Journal of The South African Institute of Mining and Metallurgy, January/February 2000, pp. 7-15.

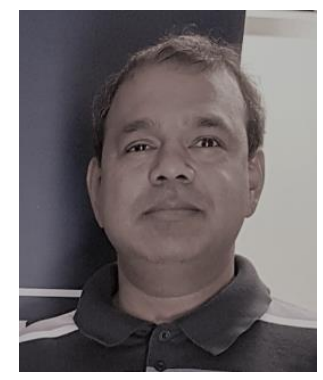

\section{Ninmaalan Naicker}

Seismology Specialist

Gold Fields

Nin has 24 years of experience in rock engineering and seismology in deep level gold mining. He has a BSc (Hons) degree in physics, a MSc (Eng) degree in mine seismology and a certificate in rock engineering. He is presently employed by South Deep gold mine where he forms part of the rock engineering department on the mine. 